\title{
A systematic review of biomechanical risk factors for the development of work-related musculoskeletal disorders in surgeons of the head and neck
}

\author{
Andrew Maxner ${ }^{\mathrm{a}, *}$, Heather Gray ${ }^{\mathrm{a}}$ and Ananth Vijendren ${ }^{\mathrm{b}}$ \\ ${ }^{a}$ Department of Physiotherapy \& Paramedicine, Glasgow Caledonian University, Glasgow, UK \\ ${ }^{\mathrm{b}}$ ENT Department, Lister Hospital, East and North Herts NHS Trust, Stevenage, UK
}

Received 24 May 2019

Accepted 3 March 2020

\begin{abstract}
.
BACKGROUND: Previous studies have shown high rates (47-72\%) of self-reported work-related musculoskeletal disorders (WRMDs) in surgeons of the head and neck. Physical requirements in the workplace, individual factors (e.g. poor posture, obesity) and psychosocial factors have been identified as risk factors. Establishing biomechanical risk factors may help prevent further development of WRMDs in this population.

OBJECTIVE: The purpose of this critical review was to source studies that identified the biomechanical risk factors for WRMDs in this surgical sub-specialty.

METHODS: Searches were conducted of Medline, CINAHL, and AMED databases from 1980 until September 2018.

RESULTS: A total of 182 article were identified. Exclusion criteria lead to 163 full-text articles being screened, generating a total of 6 articles for review. The aims of the included studies varied significantly. Surgeons spend the majority of operating time in static, asymmetrical positions. Surgical loupes/headlamps significantly increased cervical spine loading. Articulated surgical arm supports provided optimal ergonomic conditions. Performing surgical operations with the surgeon in standing or sitting had no effect on task performance or demand. Physical fatigue was also measured in both positions.

CONCLUSIONS: A combination of equipment-based and patient/surgeon position-based factors predispose surgeons to biomechanical risk factors. Studies of greater methodological quality are required.
\end{abstract}

Keywords: Work-related musculoskeletal disorders, ENT surgeons, ergonomic analysis

\section{Introduction}

Musculoskeletal disorders are a heterogenous collection of over 150 inflammatory and degenerative conditions that affect the muscles, bones, nerves, tendons, and ligaments [1, 2]. Worked-related

*Address for correspondence: Andrew Maxner, Optimize Physiotherapy, 3771 Spratt Rd \#4, Ottawa, ON K1V 2P3, Canada.

E-mail: Amaxne200@caledonian.ac.uk. musculoskeletal disorders (WRMDs), refer to musculoskeletal injuries or disorders associated with occupational aetiologic factors [3]. WRMDs can be the result of one or cumulative microtrauma and can profoundly impact an individual's quality of life [1, 4]. The World Health Organisation recognises that WRMDs are exacerbated by work-related conditions and activities and are multifactorial in nature [3, 5].

Although reports of WRMDs have been dated back to the 17 th century, more recent epidemiological studies and meta-analyses have established WRMDs as a 
major public health problem, affecting people of all ages worldwide [1, 2, 6, 7]. In 2015/16, the economic burden of WRMDs in the United Kingdom (UK) was estimated to be $\$ 14.9$ billion [8]. In 2016/17 507,000 workers in the UK were reported to be suffering from WRMDs; this accounted for $39 \%$ of all work-related ill-health and resulted in a loss of 8.9 million working days $[8,9]$. Key risk factors for developing WRMDs include physical requirements in the workplace (e.g. prolonged static postures, work specific procedures, vibrating tools), individual factors (e.g. poor posture, obesity) and psychosocial factors (e.g. shift work, work-related stress) $[2,4,7]$. While both sedentary and labour-intensive occupations have been identified as high-risk professions for the development of WRMDs, compelling evidence has suggested that surgeons also fall into that category with those operating on the head and neck susceptible to particular risk factors $[4,10,11]$.

\subsection{Literature review}

A recent meta-analysis by Epstein and colleagues [11] established high rates of WRMDs amongst 'atrisk' physicians, defined as medical interventionalists and surgeons. Twelve-month prevalence estimates of WRMDs of the neck, shoulder, back, and upper extremities reached $65 \%, 52 \%, 59 \%, 39 \%$, respectively. These results are comparable to those in highrisk, labour-intensive occupations [11]. High-rates of burnout, depression and attrition were also reported amongst physicians, necessitating the demand for intervention [11]. A UK-based survey of 325 ear, nose, and throat (ENT) surgeons found that $72 \%$ had either back or neck pain, or both [12]. Of those in pain, $53 \%$ directly attributed their symptoms to their work. Mal and Costello [13] reported higher rates (24\%) of shoulder impingement syndrome in otolaryngologists than endocrinologists in the UK. Vijendren et al. [14] surveyed 323 ENT surgeons, $47.4 \%$ of whom reported some form of WRMDs; most commonly affecting the neck and back. With the rise in the reporting of WRMDs in this surgical sub-specialty, the demand for intervention is growing [11].

Factors contributing to the development of WR MDs in ENT surgeons include long work hours, repetitive tasks, static and awkward intra-operative postures, and equipment design challenges $[11,15$, 16]. The use of microscopes, endoscopes, surgical loupes and headlamps have also been implicated in the development of WRMDs [14, 17].

\subsection{Justification for critical review}

The earlier review by Vijendren et al. [14] revealed only six articles worldwide reporting prevalence and effects of WRMDs on ENT surgeons. All studies were cross-sectional surveys and collectively reported a prevalence rate of WRMDs in $4783 \%$ of respondents [14]. No literature reviews have been identified that have critically reviewed studies that have objectively measured the biomechanical risk factors of this surgical sub-specialty to elucidate the self-report data.

The aim of this review was to identify existing articles that have assessed work-related biomechanical risk factors in surgeons of the head and neck. Establishing which risk factors are leading to the prevalence of WRMDs in this population may provide insight into the design of future job design, interventions and research.

\section{Methods}

\subsection{Research question}

The Population, Intervention, Comparison, and Outcome (PICO) framework was used to formulate the research question: "what biomechanical risk factors are leading to WRMDs in surgeons of the head and neck?".

\subsection{Types of studies}

The aim of this study was to identify articles that utilised quantitative methods. The Oxford Centre for Evidence-based Medicine classifies randomised controlled trials (RCTs) as one of the highest levels of evidence, however such trials are not always feasible in the context of evaluating surgical procedures [18]. As such, both RCTs and observational studies (cohort, case-control, and cross-sectional studies) were included. Epidemiologic and surveybased studies were excluded.

\subsection{Types of participants}

Any surgical sub-specialty that performs regular surgical operations on the head, neck or face was included. Participants of all ages and professional working years were included. 


\subsection{Types of outcome measures}

Studies were included if their primary outcome measure was an instrument that would enable the analysis of posture, muscle activity, fatigue and discomfort. No inclusion/exclusion criteria were applied to secondary outcome measures.

\subsection{Search method}

A literature search was conducted using the ProQuest platform according to Prisma-P guidelines [20], searching the Research Library, Nursing and Allied Health, Physical Education Index and Health and Medical Collection databases. The EBSCO platform was used to search the Medline, CINAHL, and AMED databases. Publication date range limitations were set from 1980 until the date of the search, September 9th, 2018. The large date range accommodated for the scarcity of literature in this field.

An extensive search strategy was created by obtaining a list of surgical subspecialties from The Royal College of Surgeons website [21]. This was then explored for job titles and keywords that could be incorporated into a surgeon specialty-based search term. Keywords that were found through literature searching were also included. Two additional sets of keywords were created; one including musculoskeletal disorder-based keywords, and another including ergonomic measurement/ergonomic analysis-based keywords (Table 1).

These three sets of keywords were then applied using the selected databases on both ProQuest and EBSCO, separated by "AND". When searching on the
EBSCO platform, the keywords were only searched in "Anywhere except full text" to maximise the relevancy of the results. Search results were limited to full text and peer-reviewed publications, to ensure access to the complete article and to optimise methodological quality. Due to comprehension issues of the researcher, a language filter was applied to only include articles of the English language. Application of limiters generated a total of 182 records, with 31 and 151 results from ProQuest and EBSCO, respectively. Duplicates were removed manually from the two platforms (19 in total), generating 163 articles for screening. A total of 4 full-text articles were identified. A citation search was performed using the PubMed platform, for each of the 4 included studies. This was to find existing literature that had not been found using the search strategy and limiters. Two additional articles were found and included.

The PRISMA flow diagram of included and excluded articles can be found in Fig. 1. Excluded studies, with rationale, can be found in the Appendix.

\section{Findings}

\subsection{Study quality}

Six studies were included for appraisal, all of which were observational studies. They were appraised using the Strengthening the Reporting of Observational Studies in Epidemiology (STROBE) statement, which has been validated in the surgical research field $[22,23]$. Three studies had a STROBE score of equal to or less than 20/35 [24, 26, 27],

Table 1

Search Strategy

Surgeon Speciality

Keywords (neuro-oncologist* OR (functional neurosurgeon*) OR (neurovascular surgeon*) OR traumatologist* OR
(skull base surgeon*) OR (spinal surgeon*) OR (oral and maxillofacial surgeon*) OR (oral surgeon*)
OR (maxillofacial surgeon*) OR (craniofacial trauma surgeon*) OR (cosmetic surgeon*) OR
(orthognathic surgeon*) OR (temporomandibular joint surgeon*) OR (temporomandibular surgeon*)
OR (ENT surgeon*) OR (ear nose and throat surgeon*) OR (ear, nose and throat surgeon*) OR
otolaryngologist* OR otorhinolaryngologist* OR (ENT surgeon*) OR otolog* OR neurotolog* OR
(thyroid surgeon*) OR (parathyroid surgeon*) OR rhinologist* OR (facial plastic surgeon*) OR
laryngologist* OR (paediatric ENT surgeon*) OR (paediatric ear, nose and throat surgeon*) OR
(paediatric eat nose and throat surgeon*) OR (pediatric ENT surgeon) OR (pediatrict ear, nose, and
throat surgeon) OR (pediatric ear nose and throat surgeon) OR (plastic and reconstructive surgeon*) OR
(plastic \& reconstructive surgeon*) OR (plastic surgeon*) OR (reconstructive surgeon*) OR (congenital
surgeon*) OR (cleft surgeon*) OR (aesthetic surgeon*) OR (facial plastic*) OR (craniofacial surgeon*)
OR neurosurgeon* OR (paediatric neurosurgeon*) OR (pediatric neurosurgeon*))
((work-related musculoskeletal disorders) OR (work-related musculoskeletal pain) OR (occupational
pain) OR (occupational musculoskeletal pain) OR (back pain) OR (neck pain) OR (shoulder pain) OR
(muscular pain) OR (wrist pain) OR (work-related musculoskeletal injur*)) OR (occupational
musculoskeletal injur*)
objective measure* OR ergonomic analysis OR ergonomic* 


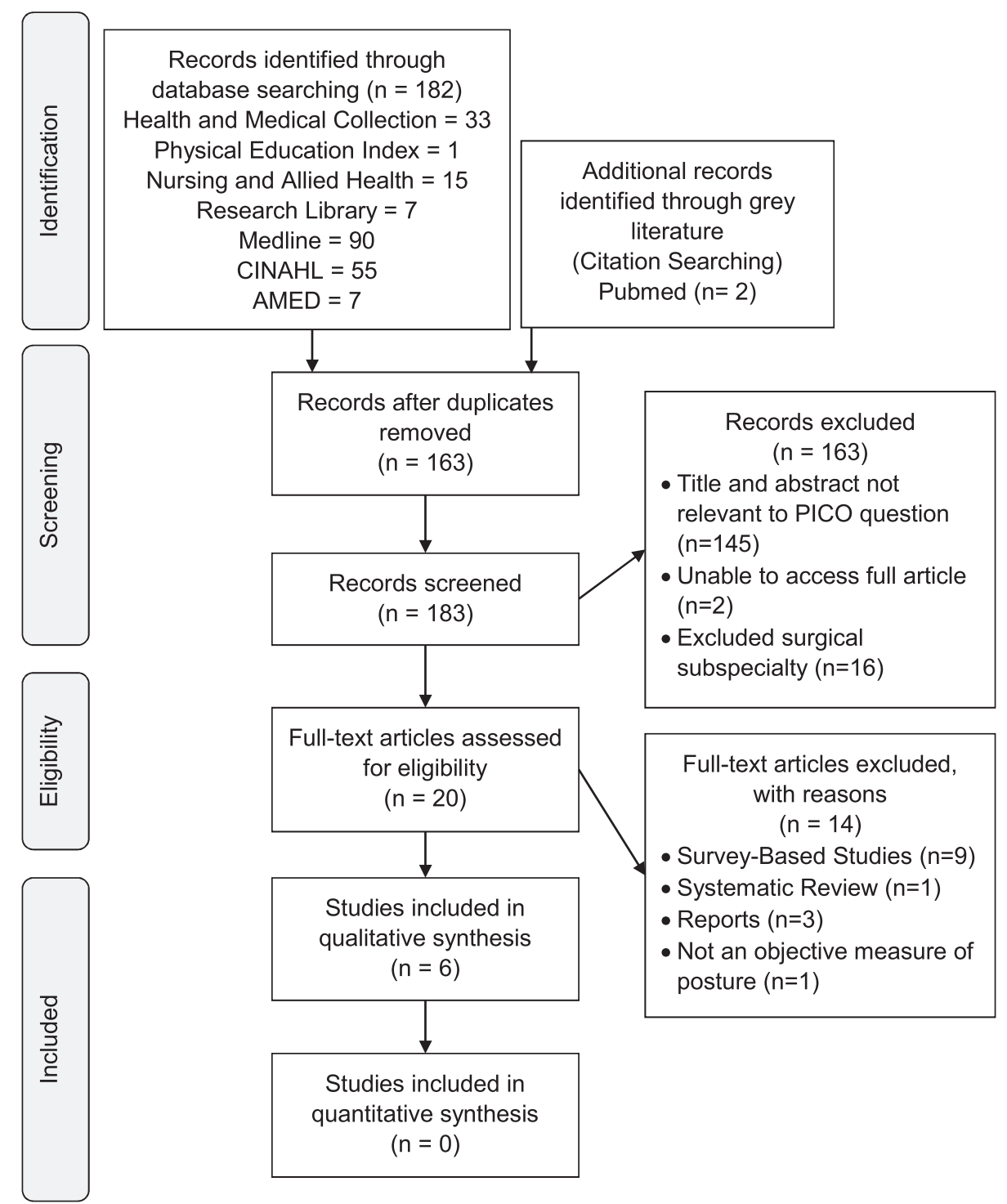

Fig. 1. PRISMA Diagram.

and three had a score higher than 20/35 [25, 28, 29] (Table 2), meeting between $49 \%-66 \%$ of the STROBE criteria. This suggests that the included articles are of a low to moderate level of quality.

\subsection{Study aims, design and findings}

The aims and results of the studies varied significantly (Table 3 ).

\subsection{Sample characteristics}

Sample sizes were small across all studies, ranging from 1-13 participants (Table 4).
Reporting of inclusion and exclusion criteria of participants was poor; no studies included eligibility criteria or recruitment strategies. Neither did they provide validation for their sample sizes. Descriptive data of study participants were universally lacking. Shaw et al. [27] were the only ones who provided the mean age of participants. While older age has been identified as a risk factor for WRMDs in surgeons, younger surgeons may also be at risk for WRMDs due to lack of experience [30]. Hence the need to include this information. Surgical experience was not reported in any studies. A positive correlation between surgical experience and time to fatigue in target muscle groups has been reported [31]. This has 
Table 2

Appraisal of Studies Using STROBE Checklist

\begin{tabular}{|c|c|c|c|c|c|c|c|c|}
\hline & & $\begin{array}{l}\text { Statham } \\
\text { et al. [24] }\end{array}$ & $\begin{array}{l}\text { Nimbarte } \\
\text { et al. [25] }\end{array}$ & $\begin{array}{c}\text { Ramakrishnan } \\
\text { and } \\
\text { Milam [26] }\end{array}$ & $\begin{array}{c}\text { Shaw } \\
\text { et al. [27] }\end{array}$ & $\begin{array}{c}\text { Govil } \\
\text { et al. [28] }\end{array}$ & $\begin{array}{c}\text { Govil } \\
\text { et al. [29] }\end{array}$ & $\begin{array}{c}\text { Subsection } \\
\text { Percentage } \\
\text { Score }\end{array}$ \\
\hline Title and & $1 \mathrm{a}-\mathrm{TiAB}$ & $\checkmark$ & & $\checkmark$ & $\checkmark$ & $\checkmark$ & $\checkmark$ & $100 \%$ \\
\hline Abstract & $1 \mathrm{~b}-\mathrm{TiAb}$ & $\checkmark$ & $\checkmark$ & $\checkmark$ & $\checkmark$ & $\checkmark$ & $\checkmark$ & $100 \%$ \\
\hline \multirow[t]{17}{*}{ Intro } & 2 - Backgr & $\checkmark$ & $\checkmark$ & $\checkmark$ & $\checkmark$ & $\checkmark$ & $\checkmark$ & $100 \%$ \\
\hline & $3-\mathrm{Obj}$ & $\checkmark$ & $\checkmark$ & & $\checkmark$ & $\checkmark$ & $\checkmark$ & $83 \%$ \\
\hline & 4 - Study Des & $\checkmark$ & $\checkmark$ & $\checkmark$ & $\checkmark$ & $\checkmark$ & $\checkmark$ & $100 \%$ \\
\hline & 5 - Settings & $\checkmark$ & $\checkmark$ & & $\checkmark$ & $\checkmark$ & $\checkmark$ & $83 \%$ \\
\hline & 6a - Eligibility \# & & & & & & $\checkmark$ & $17 \%$ \\
\hline & 6b - Match & & & & & & & $\mathbf{0 \%}$ \\
\hline & 7 - Variables & $\checkmark$ & $\checkmark$ & $\checkmark$ & & $\checkmark$ & $\checkmark$ & $83 \%$ \\
\hline & 8 - Data sources & $\checkmark$ & $\checkmark$ & $\checkmark$ & $\checkmark$ & $\checkmark$ & $\checkmark$ & $100 \%$ \\
\hline & $9-$ Bias & & & & $\checkmark$ & $\checkmark$ & $\checkmark$ & $50 \%$ \\
\hline & 10 - Study Size & & & & & & & $0 \%$ \\
\hline & 11 - Quant Var & $\checkmark$ & $\checkmark$ & $\checkmark$ & $\checkmark$ & $\checkmark$ & $\checkmark$ & $100 \%$ \\
\hline & Statistical Methods & $\checkmark$ & $\checkmark$ & $\checkmark$ & $\checkmark$ & $\checkmark$ & $\checkmark$ & $100 \%$ \\
\hline & $12 \mathrm{a}-\mathrm{Conf}$ & $\checkmark$ & $\checkmark$ & $\checkmark$ & $\checkmark$ & $\checkmark$ & $\checkmark$ & $100 \%$ \\
\hline & $12 \mathrm{~b}-$ Subgr \# & $\checkmark$ & $\checkmark$ & $\checkmark$ & $\checkmark$ & $\checkmark$ & $\checkmark$ & $100 \%$ \\
\hline & $12 \mathrm{c}-$ Miss data & & & & & & & $\mathbf{0 \%}$ \\
\hline & $12 \mathrm{~d}-$ Loss to FU & & & & & & & $0 \%$ \\
\hline & $12 \mathrm{e}-$ Sens anal & & & & $\checkmark$ & $\checkmark$ & $\checkmark$ & $50 \%$ \\
\hline \multirow[t]{11}{*}{ Results } & $13 a-$ Pat N & $\checkmark$ & $\checkmark$ & & $\checkmark$ & $\checkmark$ & $\checkmark$ & $83 \%$ \\
\hline & $13 \mathrm{~b}$ - Non-partic \# & & & & & & & $0 \%$ \\
\hline & $13 \mathrm{c}-$ Flow & & & & & & & $0 \%$ \\
\hline & $\begin{array}{l}\text { 14a - Charct } \\
\text { Descriptive Data }\end{array}$ & $\checkmark$ & $\checkmark$ & & $\checkmark$ & & & $50 \%$ \\
\hline & $14 \mathrm{~b}$ - Miss data\# & & & & & & & $0 \%$ \\
\hline & 14c-FU Time & & & & & & & $0 \%$ \\
\hline & 15 - Outc Data & $\checkmark$ & $\checkmark$ & $\checkmark$ & $\checkmark$ & $\checkmark$ & $\checkmark$ & $100 \%$ \\
\hline & $\begin{array}{l}\text { 16a - Estim Main } \\
\text { Results }\end{array}$ & $\checkmark$ & $\checkmark$ & $\checkmark$ & & $\checkmark$ & $\checkmark$ & $83 \%$ \\
\hline & $16 \mathrm{~b}-$ Bound & & & & & & & $0 \%$ \\
\hline & $16 c$ - Tranl\# & & & & & & & $0 \%$ \\
\hline & 17 - Other Analy & $\checkmark$ & $\checkmark$ & $\checkmark$ & $\checkmark$ & $\checkmark$ & $\checkmark$ & $100 \%$ \\
\hline \multirow{4}{*}{ Discussion } & 18 - Key Res & $\checkmark$ & $\checkmark$ & $\checkmark$ & $\checkmark$ & $\checkmark$ & $\checkmark$ & $100 \%$ \\
\hline & 19 - Limit & $\checkmark$ & $\checkmark$ & $\checkmark$ & $\checkmark$ & $\checkmark$ & $\checkmark$ & $100 \%$ \\
\hline & 20 - Interpret & $\checkmark$ & $\checkmark$ & $\checkmark$ & $\checkmark$ & $\checkmark$ & $\checkmark$ & $100 \%$ \\
\hline & 21 - General & & $\checkmark$ & $\checkmark$ & & $\checkmark$ & $\checkmark$ & $67 \%$ \\
\hline Other & $22-$ Fund & & & & & $\checkmark$ & & $17 \%$ \\
\hline TOTAL SCORE ${ }^{1}$ & & $20 / 35$ & $21 / 35$ & $17 / 35$ & $20 / 35$ & $23 / 35$ & $23 / 35$ & \\
\hline PERCENTAGE & & $\mathbf{5 8 \%}$ & $60 \%$ & $49 \%$ & $57 \%$ & $66 \%$ & $66 \%$ & \\
\hline SCORE & & & & & & & & \\
\hline
\end{tabular}

${ }^{1}$ Mean $=20.3 \pm 1.7($ Range $=17-23)$

been attributed to postural maladaptation of the neck and back muscles over years of adopting particular intra-operative postures [31].

Reporting of the anthropometrics of participants was minimal (Table 4). Anthropometry can vary amongst surgeons and can impact their susceptibility to the development of WRMDs. Hand size has been found to increase difficulty of using surgical tools, predisposing surgeons with smaller hands to developing WRMDs [32]. Surgeons of shorter, or taller stature, may experience different WRMDs. Only one study provided ranges for the height of their participants [25]. Two studies measured both male and female surgeons [24, 25] and one only used a male surgeon [26]. Three studies provided no information on the gender of their participants [27-29]. A 2014 survey of female surgeons found that women who were shorter and had smaller glove sizes were more likely to report physical discomfort in the hand while operating [33]. No studies reported the patient's body habitus or neck mobility, which may influence the positions held by the surgeon [28, 29]. For the purpose of generalising the findings of the studies, as well as implementing the proper intervention, it is crucial to report information on both the physician and the patient's demographics and anthropometrics. 
Table 3

Summary of Included Studies

\begin{tabular}{|c|c|c|}
\hline Authors & Location & Study Aims \\
\hline $\begin{array}{l}\text { Statham et al. } \\
{[24]}\end{array}$ & USA & $\begin{array}{l}\text { To analyse the biomechanical impact } \\
\text { of three different intraoperative } \\
\text { positions during microlaryngeal } \\
\text { surgery }\end{array}$ \\
\hline $\begin{array}{l}\text { Nimbarte et al. } \\
{[25]}\end{array}$ & USA & $\begin{array}{l}\text { To assess the impact of using loupes } \\
\text { and headlamps on the development } \\
\text { of head musculoskeletal disorders } \\
\text { in ophthalmic plastic surgeons }\end{array}$ \\
\hline $\begin{array}{l}\text { Ramakrishnan } \\
\text { and Milam } \\
\text { [26] }\end{array}$ & USA & $\begin{array}{l}\text { To compare surgeon position, sitting } \\
\text { versus standing, on physical fatigue } \\
\text { during endoscopic sinus surgery }\end{array}$ \\
\hline
\end{tabular}

Summary of Results

- Lack of arm support and unfavourable eyepiece adjustment were associated with higher RULA scores

- Use of a Mayo stand lead to increased shoulder torque moments

- Chairs with articulated arm supports led to decreased neck strain, shoulder torque and compressive forces on the L5/S1 disc space

- Surgeons adopted asymmetrical head postures in $85 \%$

of the time spent operating (bending or rotation of $>15^{\circ}$ with flexion of $>15^{\circ}$ ).

- Higher biomechanical loading on the cervical spine was correlated with postures consisting of flexion $\geq 45^{\circ}$, $15-30^{\circ}$ of bending, and $15-45^{\circ}$ of rotation

- Loading was increased by the weight of loupes and headlamps

- Standing during ESS was associated with greater subjective reports of discomfort of the lower extremities, and upper extremities in sitting $(p<0.05)$

- Hand, neck, and eye discomfort was subjectively reported in both positions $(p<0.05)$

- EMG activity was significantly $(p<0.05)$ higher in the bicep femoris in sitting, and in the bilateral medial deltoids in standing

- No difference in task performance or demand was measured between positions

Shaw et al. Canada To compare the biomechanical [27] burden of using an indirect ophthalmoscope with other surgical instruments on vitroretinal (VR) surgeons,

- Procedures performed with indirect opthalmoscope had higher levels of flexion of the neck $\left(15.6^{\circ}\right)$, back $\left(22.2^{\circ}\right)$, overall spine $\left(37.6^{\circ}\right)$ than direct procedures

- Half of indirect operating procedure time was spent in moderate neck flexion $\left(20-45^{\circ}\right)$ and rotation $\left(>20^{\circ}\right)$.

The overall spine was moderately flexed $\left(31-62^{\circ}\right)$ for $75 \%$ of indirect operating procedure time

- Direct examinations and procedures were mostly carried

Govil et al. USA $\quad \begin{aligned} & \text { To determine which patient postion } \\ & \text { (sitting vs. supine) is more } \\ & \text { ergonomically favourable for } \\ & \text { neurotologists during earwax } \\ & \text { (cerumen) removal }\end{aligned}$

Govil et al. [29]
USA
To substantiate the findings of Govil et al. [32] and determine which patient position is ergonomically during otologic procedures out in the neutral position

- Median RULA scores $(p<0.0001)$ with patient in sitting $=5$, supine $=3$

- When examined individually, RULA scores for all neurotologists significantly decreased with the patient in supine $(p<0.05)$

- Lower RULA scores of the upper and lower arm, wrist and neck were associated with positioning the patient in supine

- The median RULA scores $(p<0.0001)$ was 4.5 when the patient was placed in the sitting position, and 2.0 when the patient was placed in the supine position

- With the patient in supine lower scores were observed in the upper arm, lower arm, wrist, neck $(p<0.0001$ in all cases), and torso $(p<0.0148)$, when compared with patient's in the seated position

- When evaluated independently, RULA scores for both physicians were significantly lower in the supine position

\subsection{Surgical equipment-based risk factors}

The types of surgical equipment-based interventions that were analysed varied amongst studies. Surgical equipment included indirect ophthalmoscopes, slit-lamps and microscopes [27], loupes and headlamps [25] and three types of varying arm support [24]. The methodological quality of these three studies was strengthened by their use of comprehensive biomechanical modelling systems. Standardisation and calibration of assessment tools was consistent across all studies. Studying surgical 
Table 4

Sample Size

\begin{tabular}{|c|c|c|c|}
\hline Authors & Surgical Specialty & $\begin{array}{l}\text { Sample } \\
\text { Size }(n=)\end{array}$ & Reported Anthropometrics \\
\hline Statham et al. [24] & Laryngologists & 3 & $\begin{array}{l}\text { One male in the } 95 \text { th percentile for their } \\
\text { height, one female in the 50th percentile, } \\
\text { and one female in the } 5 \text { th percentile }\end{array}$ \\
\hline $\begin{array}{l}\text { Nimbarte et al. } \\
{[25]}\end{array}$ & $\begin{array}{l}\text { Opthalmic Plastic } \\
\text { Surgeons }\end{array}$ & 3 & $\begin{array}{l}\text { Height }(n=150.4-175.3 \mathrm{~cm}) \text {, weight } \\
(n=48-73 \mathrm{~kg}), \text { trunk length }(49-57 \mathrm{~cm}), \\
\text { shoulder width }(35-43 \mathrm{~cm}), \text { and head-neck } \\
\text { length }(n=23-36 \mathrm{~cm}) \text { ranges of their } \\
\text { participants }\end{array}$ \\
\hline $\begin{array}{l}\text { Ramakrishnan and } \\
\text { Milam [26] }\end{array}$ & $\begin{array}{l}\text { Rhinologist (Endoscopic } \\
\text { Sinus Surgery) }\end{array}$ & 1 & Surgeon was of average height and size \\
\hline Shaw et al. [27] & Vitreoretinal Surgeons & 13 & Mean height $=173.99 \mathrm{~cm}$ \\
\hline Govil et al. [28] & $\begin{array}{l}\text { Otolaryngologists } \\
\text { (Neurotologists) }\end{array}$ & 3 & No information provided \\
\hline Govil et al. [29] & $\begin{array}{l}\text { Otolaryngologists } \\
\text { (Neurotologists }\end{array}$ & 2 & No information provided \\
\hline
\end{tabular}

operations on live patients helped strengthen the validity of the findings of Shaw et al. [27] and Nimbarte at al. [25], whereas Statham et al. [24] obtained their data from photographs of surgeons in a simulated environment. Surgeons may alter their position throughout surgical procedures, as muscular fatigue develops from prolonged static posture, a finding which cannot be captured by Statham et al. [24, 34]. During data collection Statham et al. [24] used chairs that were not identical to those used in surgical procedures. Thereby limiting the internal and external validity of their findings.

However, their use of a large number $(n=66)$ of reflective markers over the entire body is a strength of their study. Biomechanical interpretation of results was well reported across all studies. Although Shaw et al. [27] included a larger total number of surgeries $(n=22)$ over 4 months, Nimbarte et al. [25] $(n=$ 16) acquired data from 16 surgeries over a greater total duration ( $n=51$ hours). While Shaw et al [27] included more participants $(n=13)$, Nimbarte et al. [25] were the only ones to include a female participant.

\subsection{Surgeon and patient position-based risk factors}

Two studies based their interventions on patient position [28, 29], while one study altered surgeon position [26]. Govil et al. [28] and Govil et al. [29] quantified their results using the Rapid Upper Limb Assessment (RULA) postural assessment tool, while Ramakrishnan and Milam [26] used surface electromyography (EMG) to quantify muscular fatigue. Although the RULA tool is effective at providing a global assessment of musculoskeletal risk, EMG readings are universally accepted to be an effective assessment tool in ergonomic assessments $[28,35]$.

The greater number of data acquisition sessions $(n=37)$ by Govil et al. [29] is a strength of this study over their previous one [28] (Table 5). The validity of the studies was improved by allowing the surgeons to adjust their equipment to reproduce their work environment. It should be noted that both studies consisted of the same research team and involved the same surgeon participants.

Table 5

Patients Used and Data Acquisition Information

\begin{tabular}{|c|c|c|c|c|}
\hline Authors & Patient Type & $\begin{array}{c}\text { Patients } \\
(n=)\end{array}$ & $\begin{array}{l}\text { Sessions of Data } \\
\text { Acquisition }(n=)\end{array}$ & $\begin{array}{c}\text { Duration of Data } \\
\text { Acquisition }\end{array}$ \\
\hline $\begin{array}{l}\text { Ramakrishnan } \\
\text { and Milam } 2016 \\
{[26]}\end{array}$ & Cadarvic Heads & 8 & $\begin{array}{l}8 \text { operations (4 standing, } \\
4 \text { sitting) }\end{array}$ & $\begin{array}{l}\text { Throughout entire } \\
\text { duration of procedures }\end{array}$ \\
\hline Govil et al. [28] & Mock Patients & 7 & $\begin{array}{l}42 \text { observations } \\
\text { (21supine, } 21 \text { sitting) }\end{array}$ & Single, simulated position \\
\hline Govil et al.[29] & Real Patients & 37 & $\begin{array}{l}48 \text { observations ( } 24 \\
\text { supine, } 24 \text { sitting) }\end{array}$ & $\begin{array}{l}\text { Position adopted by } \\
\text { surgeon for majority of } \\
\text { time }\end{array}$ \\
\hline
\end{tabular}


Table 6

Primary Outcome Measures Used

\begin{tabular}{|c|c|c|c|c|c|c|c|}
\hline Outcome Measure & & $\begin{array}{l}\text { Statham } \\
\text { et al. [24] }\end{array}$ & $\begin{array}{l}\text { Nimbarte } \\
\text { et al. [25] }\end{array}$ & $\begin{array}{c}\text { Ramakrishnan } \\
\text { and Milam } \\
2016[26] \\
\end{array}$ & $\begin{array}{c}\text { Shaw } \\
\text { et al. [27] }\end{array}$ & $\begin{array}{c}\text { Govil } \\
\text { et al. [28] }\end{array}$ & $\begin{array}{c}\text { Govil } \\
\text { et al. [29] }\end{array}$ \\
\hline \multirow[t]{3}{*}{$\begin{array}{l}\text { Motion Analysis } \\
\text { Tools }\end{array}$} & $\begin{array}{l}\text { Trigno Wireless } \\
\text { EMG System }^{2}\end{array}$ & & & & $\checkmark$ & & \\
\hline & $\begin{array}{l}\text { Functional } \\
\text { Assessment of } \\
\text { Biomechanics } \\
\text { (FAB) }\end{array}$ & & $\checkmark$ & & & & \\
\hline & VICON Peak 612 & $\checkmark$ & & & & & \\
\hline $\begin{array}{l}\text { Biomechanical } \\
\text { Analysis Tool }\end{array}$ & $\begin{array}{l}\text { 3D-Static Strength } \\
\text { Prediction } \\
\text { (3D-SSP) } \\
\text { Analysis }\end{array}$ & $\checkmark$ & & & & & \\
\hline $\begin{array}{l}\text { Electromyo- } \\
\text { graphy }\end{array}$ & $\begin{array}{l}\text { Noninvasive } \\
\text { Surface } \mathrm{EMG}^{3}\end{array}$ & & & $\checkmark$ & & & \\
\hline \multirow{2}{*}{$\begin{array}{l}\text { Postural } \\
\text { Observation } \\
\text { Tools }\end{array}$} & RULA & $\checkmark$ & & & & $\checkmark$ & $\checkmark$ \\
\hline & LUBA & & & & $\checkmark$ & & \\
\hline
\end{tabular}

${ }^{2}$ The Trigno Wireless EMG system is an accelerometer-based analysis tool [27]. ${ }^{3}$ Noninvasive surface EMG electrodes were placed on bilateral medial deltoid, upper trapezius, erector spinae, and biceps femoris muscle groups [26] 
The validity of the findings of Govil et al. [28] were limited by their use of photographs of seven mock patients. Whereas Ramakrishnan and Milam [26] acquired data by performing the operation on a cadaver, strengthening the validity of their findings (Table 5).

\subsection{Outcome measures}

The outcome measures that were used in the studies are summarised in Table 6 .

\subsubsection{Biomechanical analyses tools}

Two studies used motion capture systems to generate three-dimensional (3D) models of their participants [24, 25], considered the gold standard of motion analysis [36], and one used accelerometer-based systems to quantify inclination angles [27]. A high level of agreement has been found between accelerometers and the Vicon system (ICC $=0.774)$, with both demonstrating good reliability for movement measurements (accelerometer $=0.739$, VICON $=0.542$, $P<0.001)$ [42].

Although the Trigno Wireless EMG system used by Shaw et al. [27] has been reported to have excellent movement classification accuracy, no other literature could be found on the VICON Peak-612 or FAB [37]. No literature could be found that validated the tools with surgeons.

\subsubsection{Non-invasive surface EMG}

Non-invasive surface EMG has been established as a suitable measurement tool for assessing muscular activity in ergonomic evaluations [38]. A study of 200 participants [39] found EMG readings to have high intra-rater reliability (ICC $=0.86-88$ ); however, Ramakrishnan and Milam [26] dispute this statement claiming EMG readings can be highly variable.

\subsubsection{3-D static strength prediction program (3D-SSP) analysis}

The 3D-SSP used by Statham et al. [24] is one of the most widely used quantitative ergonomic tools. It has been found to be valid tool for predicting static strength requirements for a variety of occupational tasks [40]. Despite this, the tool has not been validated with surgeons [41]. Statham et al. [24] also state that external forces were applied to a specific joint (i.e. an elbow) rather than proportionately along the length of the segment (i.e. forearm). This may not mimic the dispersion of force along the human body and limits the generalisability of their findings to the human body.

\subsubsection{Rapid upper limb assessment (RULA) Tool}

The RULA tool was a suitable outcome measure for three of the included studies both due to its validation with static sitting postures, which resemble surgical postures, and for its ability to detect occupational conditions that warrant ergonomic intervention [24]. The RULA tool is designed to provide an overall risk assessment of musculoskeletal injury but has been criticised for the lack of evidence regarding the predictive value of the subcomponents [24]. Thereby, a causal relationship cannot be established between sub-scores on the RULA tool and the development of WRMDs in the respective area. In addition, the RULA tool has been found to have high intra-rater $(91.7 \%)$, but low inter-rater reliability $(\mathrm{ICC}<0.5)$ $[42,43]$.

\subsubsection{Loading on the upper-body assessment (LUBA) Tool}

The LUBA tool was designed to assess a workers' static postures and their subsequent risk for developing WRMDs in the upper body [42]. This was a suitable tool for Shaw et al. [27] as its classification system is in line with the aims of their study. However, the tool was developed based on a small pool of male subjects $(n=20)$ and has not been validated in a surgical environment, thus limiting its external validity [44].

\subsection{Analysis}

Large periods of time spent in asymmetrical cervical postures during operating time were reported by Statham et al. [24], Nimbarte et al. [25] and Shaw et al. [27]. Surgeons adopted asymmetrical cervical postures for $85 \%$ of operating time [25]. An asymmetrical posture was defined as lateral flexion or rotation of the cervical spine greater than $15^{\circ}$, coupled with flexion greater than $15^{\circ}$. Surgeons spent $65 \%$ of operating time in a low loading zone, and 35\% in medium-high loading zones (Table 7). Moderate cervical flexion $\left(20-45^{\circ}\right)$ was reported during $42 \%$, and rotation $\left(>20^{\circ}\right)$ during $77 \%$ of examinations that involved an indirect ophthalmoscope [31]. The overall spine was found to be moderately flexed (31-62 $)$ during $76.3 \%$ of these examinations. Surgical procedures involving the indirect ophthalmoscope were associated with moderate cervical flexion and rotation of during $50 \%$ of operating times. The overall 
Table 7

Cervical Loading Zones, Adapted from Nimbarte et al. [25]

\begin{tabular}{lccc}
\hline & Flexion & Rotation & $\begin{array}{c}\text { Lateral } \\
\text { Flexion }\end{array}$ \\
\hline Low Loading Zone & $15-30^{\circ}$ & $15-45^{\circ}$ & $20^{\circ}$ \\
Medium & $20^{\circ}$ & $15-45^{\circ}$ & $35^{\circ}$ \\
Loading Zone & $30^{\circ}$ & $15-30^{\circ}$ & $30^{\circ}$ \\
High Loading Zone & $45^{\circ}$ & $15-45^{\circ}$ & $15-30^{\circ}$ \\
& $30^{\circ}$ & $30-45^{\circ}$ & $30^{\circ}$ \\
\hline
\end{tabular}

spine was recorded to be in moderate flexion during $76 \%$ of operating times. Procedures and examinations that did not involve the indirect ophthalmoscope were associated with near neutral $\left(<15^{\circ}\right.$ deviation from neutral in any direction) postures.

The use of loupes and headlamps was associated with a mean increase of cervical loading of $40 \%$ [25]. This effect was amplified in postures involving cervical flexion $\geq 45^{\circ}$ and lateral flexion of $15-30^{\circ}$.

Operative chairs with articulated arm supports led to a lower RULA score and decreased levels of neck flexion, in comparison to chairs with a Mayo stand or no arm support at all [24]. A difference in shoulder torque of $30 \mathrm{Nm}$ was reported between arms-supported and Mayo stand position, suggesting that the Mayo stand was less favourable. When compared to a supported position, the unsupported arm position caused a near four-fold increase in compressive forces at the L5-S1 disc space. Unfavourable ergonomic positions were associated with placing the adjustable eye pieces of microscopes upside down, causing cervical extension. A Trendelenburg table positioning, which involved angling the operative table so that the patient's feet were are above their head, was found to be more ergonomically favourable for the surgeon [24]. A Trendelenburg bed angle of -7 to $-12^{\circ}$ in the horizontal plane were used and no $p$-values were provided by the authors [24].

Having the patient positioned in the supine position was associated with lower RULA scores $(p<0.0001)$ than in sitting $[28,29]$. RULA sub-scores were significantly lower in the upper arm, lower arm, wrist and neck in both studies ( $p$-values ranging from $<0.0001$ -0.0020 ). Neither study included the point distribution within each sub-score of the RULA worksheet. Thus, it was impossible to calculate the ranges of motion that were measured at each body part. Overall RULA scores $(p=0.98)$ and subcategory scores ( $p>0.39$ for all) were not significantly different when comparing procedures performed on the patient's left or right ear [29].
Ramakrishnan and Milam [26] noted a general decrease in EMG in the upper extremity musculature during sitting dissections, and in the lower extremity during standing dissections. A decrease in mean power frequency was noted in both right and left hamstring muscle groups in standing. The left and right medial deltoids had a lower mean power frequency in standing. This trend was not observed when sitting, suggesting that standing during surgical procedures is more favourable for the deltoid musculature. The authors suggest that these differences are indicative of muscular fatigue, although the results did not achieve statistical significance $(p>0.05)$. EMG activity of the left bicep femoris was found to be significantly $(p<0.05)$ higher in the sitting dissection, suggesting that sitting is more favourable for the left hamstring musculature. No values were given for the EMG readings, therefore the author was unable to calculate percent differences between sitting and standing results.

\section{Discussion}

This purpose of this literature review was to find peer reviewed journal articles assessed work-related biomechanical risk factors in surgeons of the HNF. The findings have been summarised in Table 3 .

Three of the included studies were of greater methodological quality when using the STROBE checklist (Table 2) $[25,28,29]$. Four of the included studies incorporated robust, highly precise outcome measures, which helped strengthen the findings of this review [24-27]. Although only two of the studies involved real patients [25, 27], their findings were further strengthened by the comprehensive biomechanical modelling systems used to interpret their results. Limitations of this literature review are the small samples of all included studies and the inability to blind participants (Hawthorne Effect). Additionally, reporting of anthropometric data, and inclusion and exclusion criteria, was poor across all studies.

The conclusions of the current review that surgeons spend prolonged periods of time in neck flexion, is consistent with previous studies [45, 46]. Prolonged static neck flexion has been associated with localized muscular fatigue and pain of the neck extension musculature which can lead to subsequent biomechanical load on the cervical intervertebral discs [25, 47]. As little as $10^{\circ}$ of static neck flexion can require $5-7 \%$ of the maximum voluntary contraction of the cervical neck extensors, which is sufficient to predispose 
an individual to musculoskeletal neck pain due to the associated muscle fatigue and subsequent biomechanical load on passive structures [24]. This suggests that the neutral to moderate levels $\left(15-45^{\circ}\right)$ (Table 3 ) of prolonged cervical flexion observed may be sufficient to predispose surgeons to the development of occupational neck pain $[24,25,27]$.

Interestingly, a causal relationship between cervical rotation and neck pain has not been established in scientific literature [48]. However, this literature review suggests that surgeons adopt prolonged static postures with moderate amounts of cervical rotation $\left(20-45^{\circ}\right)$ (Table 3) during intraoperative procedures. Despite the lack of supporting literature, this is a posture to which attention should be paid in the design of future interventions, as prolonged cervical rotation is associated with increased activity of the anterior neck musculature, which may contribute to the development of work-related neck pain [49].

\subsection{Equipment-based risk factors}

The ergonomic burden of using the aforementioned surgical equipment has been well documented in scientific literature $[18,46,50]$. The use of slit lamp biomicroscopy and indirect ophthalmoscopy has been associated with increased anterior deltoid and cervical trapezius muscle activity [46]. These increases in muscle activity may be associated with the lack of arm support during microscopic work, and the slumped position that surgeons adopt to approximate themselves to the microscope $[50,51]$. This may provide a physiological rational for the musculoskeletal pain reported from surgeons, which is strengthened by the prolonged asymmetrical static postures observed while this equipment is being used [27]. The use of articular arm supports significantly decreased the biomechanical stress on the surgeon [24], which was consistent with a 2012 Cochrane Review [7].

\subsection{Surgeon and patient position-based risk factors}

While the only result from Ramakrishnan and Milam [26] that reached statistical significance was the left hamstring group in the sitting position, the authors suggest that the general decrease in EMG activity is indicative of the sitting being more favourable for the lower limb musculature and standing for the upper limb. With no discernible pattern emerging from survey data, the optimal intra-operative posture may be surgeon-specific and determined by individual factors such as previous musculoskeletal injuries, personal preferences and present workload [26]. A 2005 systematic review of ergonomics during endoscopic surgery highlighted the difficulty of evaluating an optimal posture during surgery, due to the influences of static and dynamic postural stresses [52]. Prolonged static postures were identified as being a principle cause of the development of musculoskeletal complaints in laparoscopists [52]. Therefore, the difficulty in objectively measuring an ideal posture, as well as the lack of a subjectivelyreported preferred position, suggest that the ideal posture may be surgeon and operation specific [26]. Recent evidence suggests that the breaking of static postures can decrease the onset of pain and intensity of muscular contractions, suggesting that a key preventative strategy may be avoiding a posture for an extended period of time [17].

Little surgical-based evidence exists to reinforce the findings of Govil et al. [28] and Govil et al. [29], as the patient is most commonly placed in the supine position throughout surgery. However, a supine position is recognised as the most favourable patient position in a dentistry setting, a finding which may be generalisable to surgeons performing procedures in outpatient clinics [53]. An important finding of these two studies is the subsequent decrease in upper arm and neck RULA scores obtained when placing the patient in supine versus in sitting (Table 3), both of which are areas that are susceptible to the development of WRMDs in this population [13, 14].

\subsection{Implications}

The findings of this literature review may be generalisable to other professions that share similar postural requirements and use similar equipment, such as dentists, dental surgeons, and pathologists [51, 54, 55]. However, caution must be taken when generalising these findings as, other professions may differ in static posture position, duration, equipment and workplace ergonomics. Figure 2 proposes an optimal posture for surgeons when performing procedures in the operating room and in an outpatient clinic.

During tasks performed intra-operatively and in an outpatient clinic, surgeons should aim to maintain an anatomically neutral posture and avoid asymmetri$\mathrm{cal}$, extreme/end of range postures. Maintenance of a near-neutral posture is especially important when using equipment that may increase the biomechanical loading on the surgeon's body [27]. When possible, 


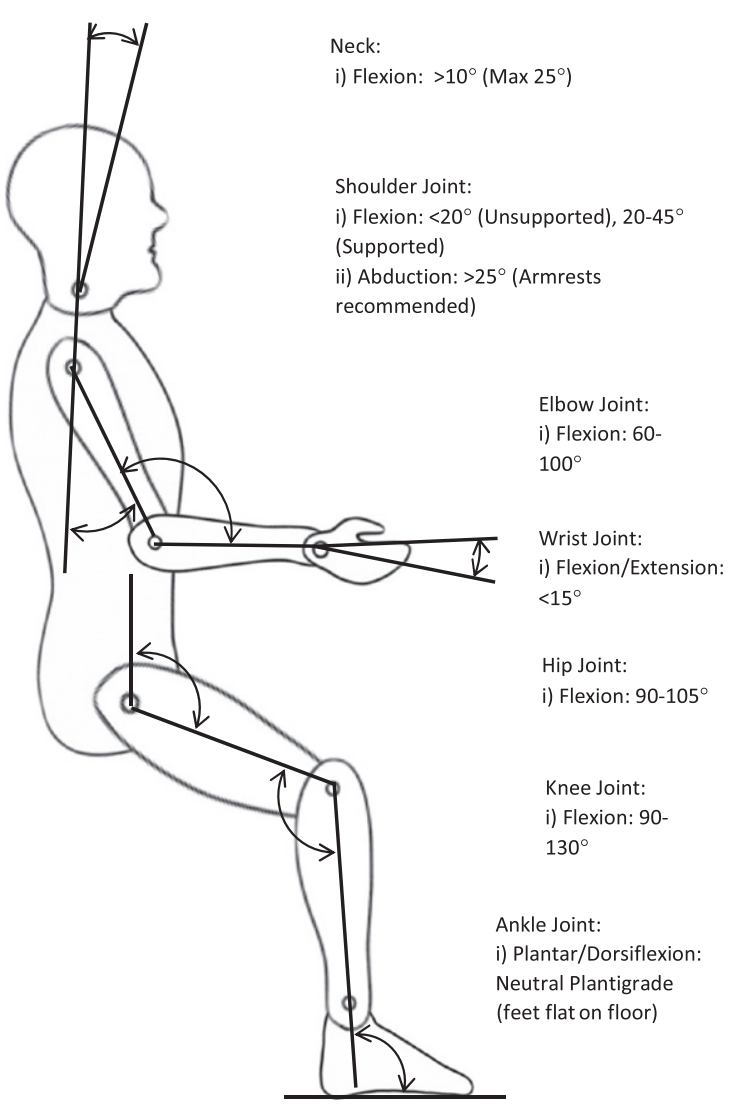

Fig. 2. Recommended Surgical Posture and Joint Positions [24, $27,51,56]$.

surgeons should utilise a Trendelenburg table tilt to minimise their ergonomic risk [24]. Surgeons can reduce the biomechanical load on the lumbar spine by approximating themselves to the patient [24].

Positioning the patient in a supine position during procedures in the operating room and in outpatient clinics, may improve surgeon positioning [28, 29]. The choice of whether to perform surgical procedures in sitting or standing should be individualised. Surgeons should prioritise one position over the other based on previous musculoskeletal injuries and personal preference. Moreover, they should consider alternating between the two to break up static postures $[26,52,57]$. When operating in a seated position, articulated arm supports are recommended to avoid biomechanical strain [24].

Alrashed [51] suggested the use of a lightweight ophthalmoscope, and to position the slit lamp at the beginning of the workday, adjusting patient position accordingly. Workstation features, such as surgical stool height, operating room table height, monitor placement, and microscope position, should be personalised by the surgeon based on their anthropometrics, and personal preference [51, 52, 58-61]. Optimisation of the surgical theatre environment can improve individual surgeon skill and satisfaction, as well as promote safety [57].

A recent systematic review found the implementation of a saddle seat during surgical procedures to be effective in reducing musculoskeletal discomfort in the neck, back, shoulder and arm in microsurgeons [62]. Favourable subjective and objective results of fatigue and pain in the neck and back in ENT surgeons have been reported with the use of a prototype postural support chair [31].

The use of intraoperative microbreaks during surgical procedures has been highlighted in recent literature, providing evidence that 20 second breaks every 20 minutes can help reduce musculoskeletal pain, improving physical performance and mental focus [63, 64]. The Ipswitch Microbreak Technique, coined by Vijendren et al. [17] found similar improvements with the use of microbreaks on the onset of fatigue and pain in the neck and upper shoulder muscle groups during microscopic procedures.

\subsection{Model of practice}

An individual's psychological risk factors and perception of work, known as Yellow and Blue Flags, respectively, are associated with the manifestation of WRMD symptoms and are a predictor of disability $[65,66]$. Due to the multifactorial nature of WRMDs, it is pivotal that a biopsychosocial approach be taken when implementing interventions targeting at addressing these disorders [2, 66]. A Model of Practice has been proposed in Fig. 3.

\subsection{Policy implications}

The implementation of policies that allow surgeons to implement intraoperative ergonomic adjustments to their surgical instruments and surgical environment based on their habitus may be beneficial due to the growing evidence in their efficacy in reducing workrelated pain $[33,58]$.

A 2012 ergonomic survey of ENT surgeons [68] highlighted their lack of awareness of ergonomic principles, despite the high prevalence of WRMDs; a finding that has been reported across multiple surgical specialties by meta-analysis [11]. The authors advocated for the implementation of surgical ergonomic strategies for practitioners, and to implement 


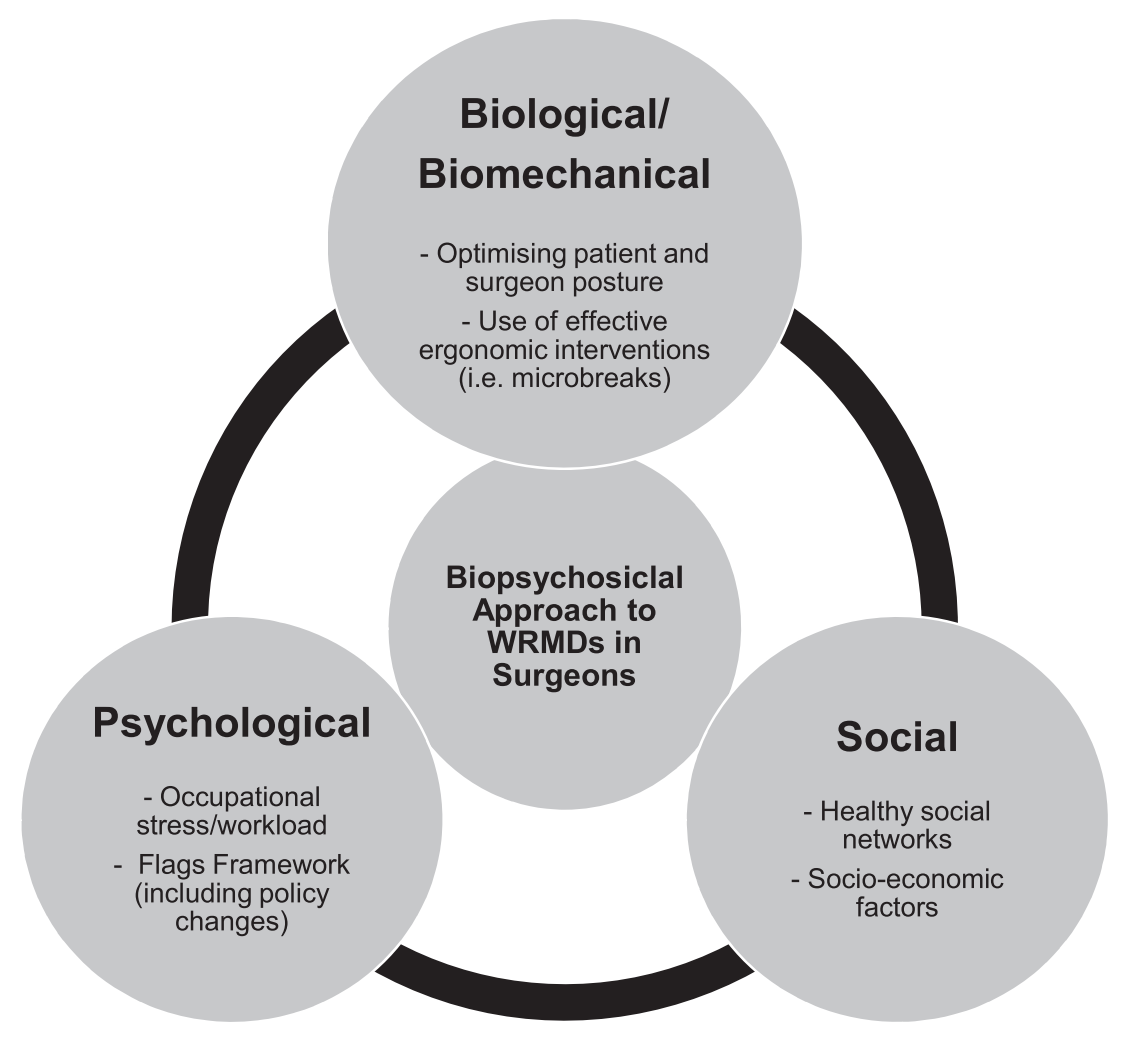

Fig. 3. Model of Practice [64].

ergonomic knowledge-based interventions at the education level [68].

Policy changes may look to incorporate intra/interoperative rest breaks and minimise overtime hours, as these factors may increase the surgeon's risk of developing WRMDs [51].

\subsection{Research implications}

Future research may look to assess the impact of ergonomic-based (e.g. saddle seats, prototype chairs) and surgeon-based interventions (e.g. microbreaks) to assess their effect on musculoskeletal fatigue and pain, and task performance. Future studies should endeavour to use real life patients in order to strengthen the validity of their findings. Thorough documentation of surgeon and patient anthropometrics and establishing a relationship between their body size and posture during occupational tasks, is paramount to producing results that are generalisable to surgeons of varying body types. The focus of this review was predominantly on the biological/biomechanical domain of the Model of Practice proposed in Fig. 3. Future studies may look to also incorporate outcome measures that assess the psychological and social domains to fully encompass the multifactorial nature of WRMDs.

\subsection{Limitations}

The generalisability of the results to surgeons in the UK may be limited, as the included studies only took place in Canada and the United States. The inclusion of only English-based studies may have caused studies of other languages to be missed in the search strategy. The results may be susceptible to single reviewer bias.

\section{Conclusion}

This review elucidates the key biomechanical risk factors and proposed interventions for surgeons of the head and neck adopt postures consisting of moderate amount of cervical flexion and rotation. The use of loupes and headlamps significantly increases the biomechanical load on the cervical spine in postures that deviated from neutral; articulated arm 
supports were beneficial in reducing shoulder torque and lumbar spine strain; placing the patient in a supine position reduced ergonomic risk; and sitting or standing positions were equally as favourable, biomechanically, for the surgeon.

\section{Conflict of interest}

\section{None to report.}

\section{References}

[1] Punnett L, Wegman DH. Work-related musculoskeletal disorders: the epidemiologic evidence and the debate. Journal of Electromyography and Kinesiology [Internet]. 2004 [cited 2018 Sept 21]; 4:13-23. Available from: https//doi. org/10.1016/j.jelekin.2003.09.015

[2] World Health Organization, 2018 [Internet]. [cited 2018 Sept 21].Musculoskeletal conditions. https://www.who. int/mediacentre/factsheets/musculoskeletal/en/

[3] Bernhard BP. A critical review of epidemiological evidence for work-related musculoskeletal disorders of the neck, upper extremity and low back. Musculoskeletal Disorders and Workplace Factors. Cincinnati (United States of America): National Institute for Occupational Safety and Health [Internet];1997 [cited 2018 Sept 21]. Available from: https://www.cdc.gov/niosh/docs/97-141/pdfs/97-141.pdf

[4] Health and Safety Executive. Work-related ill health and occupational disease in Great Britain. Great Britain: Health and Safety Executive [Internet]; 2018 [cited 2018 September 12]. Available from: http://www.hse.gov. uk/statistics/causdis/

[5] World Health Organization. Identification and Control of Work-Related Diseases. Geneva (Switzerland): World Health Organization [Internet];1985 [Cited 2018 September 21]. Available from: http://www.who.int/iris/handle/ 10665/40176

[6] Ramazzini B. De morbis artificum diatriba [diseases of workers]. American Journal of Public Health [Internet]. 2001 [cited 2018 September 22]; 91:1380-2. Available from: https://doi.org/10.2105/AJPH.91.9.1380

[7] Hoe VC, Urquhart DM, Kelsall HL, Sim MR. Ergonomic design and training for preventing work-related musculoskeletal disorders of the upper limb and neck in adults. Cochrane Database of Systematic Reviews [Internet]. 2012 [cited 2018 Sept 22]; 8. Available from: https://doi. org/10.1002/14651858.CD008570.pub2.

[8] Health and Safety Executive. Costs to Great Britain of workplace injuries and new cases of work-related ill health - 2016/17. Health and Safety Executive [Internet]. Great Britain, 2018 [cited 2018 Sept 21]. Available from: http:// www.hse.gov.uk/statistics/cost.htm

[9] Cheng HY, Cheng CY, Ju YY. Work-related musculoskeletal disorders and ergonomic risk factors in early intervention educators. Applied Ergonomics [Internet]. 2013 [cited 2018 Sept 21]; 44:134-41. Available from: https://doi. org/10.1186/s12889-016-2777-7

[10] Schneider E, Copsey S, Irastorza X. OSH [Occupational Safety and Health] in Figures: Work-related
Musculoskeletal Disorders in the EU-Facts and Figures. Office for Official Publications of the European Communities [Internet]. 2010 [cited 2018 Sept 21]. Available from: https://doi.org/10.2802/10952

[11] Epstein S, Sparer EH, Tran BN, Ruan QZ, Dennerlein JT, Singhal D, Lee BT. Prevalence of Work-Related Musculoskeletal Disorders Among Surgeons and Interventionalists: A Systematic Review and Meta-analysis. JAMA Surgery [Internet]. 2018 [cited 2018 Sept 9];153:e174947. Available from: https://doi.org/10.1001/jamasurg.2017. 4947

[12] Babar-Craig H, Banfield G, Knight J. Prevalence of back and neck pain amongst ENT consultants: national survey. The Journal of Laryngology \& Otology [Internet]. 2003 [cited 2018 Sept 25];117:979-82. https://doi.org/ $10.1258 / 002221503322683885$

[13] Mal RK, Costello CH. Is shoulder impingement syndrome a problem in otolaryngologists? Clinical Otolaryngology \& Allied Sciences [Internet]. 2002 [cited 2018 Sept 25];1:44-7. Available from: https://doi.org/10.1046/j.03077772.2001.00521.x

[14] Vijendren A, Yung M, Sanchez J, Duffield K. Occupational musculoskeletal pain amongst ENT surgeons-are we looking at the tip of an iceberg?. The Journal of Laryngology \& Otology [Internet]. 2016 [cited 2018 Sept 25]; 130:490-6. Available from: https://doi.org/10.1017/ S0022215116001006

[15] Bolduc-Bégin J, Prince F, Christopoulos A, Ayad T. Work-related musculoskeletal symptoms amongst Otolaryngologists and Head and Neck surgeons in Canada. European Archives of Oto-Rhino-Laryngology [Internet]. 2018 [cited 2016 September 25];275:261-7. Available from: https://doi.org/10.1007/s00405-017-4787-1

[16] Kitzmann AS, Fethke NB, Baratz KH, Zimmerman MB, Hackbarth DJ, Gehrs KM. A survey study of musculoskeletal disorders among eye care physicians compared with family medicine physicians. Ophthalmology [Internet]. 2012 [cited 2018 Sept 25]; 119:213-20. Available from: https://doi.org/10.1016/j.ophtha.2011.06.034

[17] Vijendren A, Devereux G, Tietjen A, Duffield K, Van Rompaey V, Van de Heyning P, Yung M. The Ipswich Microbreak Technique to alleviate neck and shoulder discomfort during microscopic procedures. Applied Ergonomics [Internet]. 2018 [cited 2018 Sept 25];S0003-6870:1. Available from: https://doi.org/10.1016/j.apergo.2018.04.013

[18] Oxford Centre for Evidence-Based Medicine. Oxford Centre for Evidence-based Medicine - Levels of Evidence (March 2009). 2009. Centre for Evidence-Based Medicine [Internet]. Great Britain [cited 2019 February 24]. Available from: https://www.cebm.net/

[19] Song JW, Chung KC. Observational studies: cohort and case-control studies. Plastic and Reconstructive Surgery [Internet]. 2010 [cited 2018 Sept 25]; 126:2234. Available from: https://doi.org/10.1097/PRS.0b013e3181f44abc

[20] Shamseer L, Moher D, Clarke M, Ghersi D, Liberati A, Petticrew M, Shekelle P, Steward LA. Preferred reporting items for systematic review and meta-analysis protocols (PRISMA-P) 2015: elaboration and explanation. The British Medical Journal [Internet]. 2015 [cited 2019 February 24]. Available from: https://doi.org/10.1136/bmj.g7647

[21] Royal College of Surgeons. Surgical specialties. Royal College of Surgeons [Internet]. 2018 [cited 2018 September 25]. Available from: https://www.rcseng.ac.uk/careers-insurgery/trainees/foundation-and-core-trainees/surgicalspecialties/ 
[22] Vandenbroucke JP, Von Elm E, Altman DG, Gøtzsche PC, Mulrow CD, Pocock SJ, Poole C, Schlesselman JJ, Egger M, Strobe Initiative. Strengthening the Reporting of Observational Studies in Epidemiology (STROBE): explanation and elaboration. PLoS Medicine [Internet]. 2007 [cited 2018 Sept 26];16;4:e297. Available from: https:// doi.org/10.1371/journal.pmed.0040297.t001

[23] Sorensen AA, Wojahn RD, Manske MC, Calfee RP. Using the STROBE Statement to Assess Reporting of Observational Trials in Hand Surgery. The Journal of Hand Surgery [Internet]. 2013 [cited 2018 Sept 25];38:1584. Available from: https://doi.org/10.1016/j.jhsa.2013.05.00

[24] Statham MM, Sukits AL, Redfern MS, Smith LJ, Sok JC, Rosen CA. Ergonomic analysis of microlaryngoscopy. The Laryngoscope [Internet]. 2010 [cited 2018 Sept 25];120:297-305. Available from: https://doi.org/10. 1002/lary.20686

[25] Nimbarte AD, Sivak-Callcott JA, Zreiqat M, Chapman M. Neck postures and cervical spine loading among microsurgeons operating with loupes and headlamp. IIE Transactions on Occupational Ergonomics and Human Factors [Internet]. 2013 [cited 2018 Sept 25];4:215-23. Available from: https://doi.org/10.1080/21577323.2013.840342

[26] Ramakrishnan VR, Milam BM. Ergonomic analysis of the surgical position in functional endoscopic sinus surgery. In International Forum of Allergy \& Rhinology [Internet]. 2017 [cited 2018 Sept 25]; 7:570-5. Available from: https://doi.org/10.1002/alr.21911

[27] Shaw C, Bourkiza R, Wickham L, Mccarthy I, Mckechnie C. Mechanical exposure of ophthalmic surgeons: a quantitative ergonomic evaluation of indirect ophthalmoscopy and slit-lamp biomicroscopy. Canadian Journal of Ophthalmology/Journal Canadien d'Ophtalmologie [Internet]. 2017 [cited 2018 Sept 25];52:302-7. Available from: https://doi.org/10.1016/j.jcjo.2016.09.011

[28] Govil, N., DeMayo, W.M., Hirsch, B.E. and McCall, A.A. Optimizing positioning for in-office otology procedures. Otolaryngology-Head and Neck Surgery [Internet]. 2017 [cited 2018 Sept 25];156:156-160. Available from: http://doi.org/10.1177/0194599816670137

[29] Govil N, DeMayo WM, Hirsch BE, McCall AA. Patient Positioning During In-Office Otologic Procedures Impacts Physician Ergonomics. Otology \& Neurotology [Internet]. 2018 [cited 2018 Sept 25];39(9):883-8. Available from: https://doi.org/10.1097/MAO.0000000000001961

[30] Dabholkar TY, Yardi SS, Dabholkar YG. Prevalence of work-related musculoskeletal symptoms in surgeons performing minimally invasive surgery: a review of literature. International Surgery Journal [Internet]. 2016 [cited 2018 Sept 25];3:1028-34. Available from: http://dx.doi. org/10.18203/2349-2902.isj20161437

[31] Vijendren A, Devereux G, Kenway B, Duffield K, Van Rompaey V, Van de Heyning P, Yung M. Effects of prolonged microscopic work on neck and back strain amongst male ENT clinicians and the benefits of a prototype postural support chair. International Journal of Occupational Safety and Ergonomics [Internet]. 2017 [cited 2018 Sept 25];1:10. Available from: https://doi.org/10.1080/10803548.2017. 1386411

[32] Berguer R, Hreljac A. The relationship between hand size and difficulty using surgical instruments: a survey of 726 laparoscopic surgeons. Surgical Endoscopy and Other Interventional Techniques [Internet]. 2004 [cited 2018 Sept 26];18:508-12. Available from: https://doi.org/ 10.1007/s00464-003-8824-3
[33] Sutton E, Irvin M, Zeigler C, Lee G, Park A. The ergonomics of women in surgery. Surgical Endoscopy [Internet]. 2014 [cited 2018 September 26]; 28:1051-5. Available from: https://doi.org/10.1007/s00464-013-3281-0

[34] Yoon SH, Jung MC, Park SY. Evaluation of surgeon's muscle fatigue during thoracoscopic pulmonary lobectomy using interoperative surface electromyography. Journal of Thoracic Disease [Internet]. 2016 [cited 2018 Sept 26]; 8:1162. Available from: https://doi.org/10. 21037/jtd.2016.04.16

[35] Thuresson M, Äng B, Linder J, Harms-Ringdahl K. Mechanical load and EMG activity in the neck induced by different head-worn equipment and neck postures. International Journal of Industrial Ergonomics. 2005 [cited 2018 Oct 2]; Jan 1;35(1):13-8. Available from: https://doi. org/10.1016/j.ergon.2004.06.008

[36] Chung PY, Ng GY. Comparison between an accelerometer and a three-dimensional motion analysis system for the detection of movement. Physiotherapy [Internet]. 2012 [cited 2018 Oct 2]; 98:256-9. Available from: https://doi.org/10.1016/j.physio.2011.06.003

[37] Pizzolato S, Tagliapietra L, Cognolato M, Reggiani M, Müller H, Atzori M. Comparison of six electromyography acquisition setups on hand movement classification tasks. PloS one [Internet]. 2017 [cited 2018 Oct 2]; 10:0186132. Available from: https://doi.org/10.1371/jour nal.pone. 0186132

[38] Sušić A, Jurčević Lulić T, Veljović F. Ergonomic evaluation of task execution: Surface electromyography in muscular activity screening. Periodicum Biologorum [Internet]. 2010 [cited 2018 Oct 2];1121:33-8. Available from: http://orcid.org/0000-0001-9502-9276

[39] Edgerton VR, Wolf SL, Levendowski DJ, Jennrich RI, Roy RR. EMG activity in neck and back muscles during selected static postures in adult males and females. Physiotherapy Theory and Practice [Internet]. 1997 [cited 2018 Oct 2]; 13:179-95. Available from: https://doi.org/ 10.3109/09593989709036462

[40] Chaffin DB. Development of computerized human static strength simulation model for job design. Human Factors and Ergonomics in Manufacturing \& Service Industries [Internet]. 1997 [cited 2018 Oct 2]; 74:305-22. Available from: https://doi.org/10.1002/(SICI)1520-6564(199723) 7:4<305::AID-HFM3>3.0.CO;2-7

[41] La DJ. An Evaluation of Female Arm Strength Predictions based on Hand Location, Arm Posture and Force Direction [Doctoral dissertation]. [cited 2018 Oct 2]. Hamilton: University of McMaster. Available from: http:// hdl.handle.net/11375/11230

[42] Kee D, Karwowski W. A comparison of three observational techniques for assessing postural loads in industry. International Journal of Occupational Safety and Ergonomics [Internet]. 2007 [cited 2018 Oct 5];13:3-14 Available from: https://doi.org/10.1080/10803548.2007.11076704

[43] Robertson M, Amick III BC, DeRango K, Rooney T, Bazzani L, Harrist R, Moore A. The effects of an office ergonomics training and chair intervention on worker knowledge, behavior and musculoskeletal risk. Applied Ergonomics [Internet]. 2009 [cited 2018 Oct 5];401:12435. Available from: https://doi.org/10.1016/j.apergo.2007. 12.009

[44] Kee D, Karwowski W. LUBA: an assessment technique for postural loading on the upper body based on joint motion discomfort and maximum holding time. Applied Ergonomics [Internet]. 2001 [cited 2018 
Oct 5];32:357-66. Available from: https://doi.org/10. 1016/S0003-6870(01)00006-0

[45] Szeto GP, Cheng SW, Poon JT, Ting AC, Tsang RC, Ho P. Surgeons' static posture and movement repetitions in open and laparoscopic surgery. Journal of Surgical Research [Internet]. 2012 [cited 2018 Oct 5];172:19-31. Available from: https://doi.org/10.1016/j.jss.2011.08.004

[46] Sivak-Callcott JA, Mancinelli CA, Nimbarte AD. Cervical occupational hazards in ophthalmic plastic surgery. Current Opinion in Ophthalmology [Internet]. 2015 [cited 5 Oct 2018];26:392-8. Available from: https://doi. org/10.1097/ICU.0000000000000182

[47] Villanueva MB, Jonai H, Sotoyama M, HISANAGA N, TAKEUCHI Y, SAITO S. Sitting posture and neck and shoulder muscle activities at different screen height settings of the visual display terminal. Industrial Health [Internet]. 1997 [cited 2018 Oct 10];35:330-6. Available from: https://doi.org/10.2486/indhealth.35.330

[48] Ariens GA, Bongers PM, Douwes M, Miedema MC, Hoogendoorn WE, van der Wal G, Bouter LM, van Mechelen W. Are neck flexion, neck rotation, and sitting at work risk factors for neck pain? Results of a prospective cohort study. Occupational and Environmental Medicine [Internet]. 2001 [cited 2018 Oct 10];58:200-7. https://doi.org/ 10.1136/oem.58.3.200

[49] Pascarelli EF, Hsu YP. Understanding work-related upper extremity disorders: clinical findings in 485 computer users, musicians, and others. Journal of Occupational Rehabilitation [Internet]. 2001 [cited 2018 Oct 10];11:1-21. Available from: https://doi.org/10.1023/A:1016647923501

[50] Honavar SG. Head up, heels down, posture perfect: Ergonomics for an ophthalmologist. Indian Journal of Ophthalmology [Internet]. 2017 [cited 2018 Oct 15];65:647. https://doi.org/10.4103/ijo.IJO_711_17

[51] Alrashed WA. Ergonomics and work-related musculoskeletal disorders in ophthalmic practice. Imam Journal of Applied Sciences [Internet]. 2016 [cited 2018 Oct 10]; 1:48. Available from: https://doi.org/10.4103/ijas.ijas_24_16

[52] Ayad T, Peloquin L, Prince F. Ergonomics in endoscopic sinus surgery: systematic review of the literature. Journal of Otolaryngology [Internet]. 2005 [cited 2018 Oct 16]: 34:333-40. Available from: https://www.ncbi.nlm. nih.gov/pubmed/16181596

[53] Gupta A, Manohar Bhat TM, Bansal N, Gupta G. Ergonomics in dentistry. International Journal of Clinical Pediatric Dentistry [Internet]. 2014 [cited 2018 Oct 16]; 7:30. Available from: https://doi.org/10.5005/jp-journals10005-1229

[54] George E. Occupational hazard for pathologists: microscope use and musculoskeletal disorders. American Journal of Clinical Pathology. 2010 [cited 2018 Sept 21]; 133:543-8. Available from: https://doi.org/10.1309/ AJCPUXDS5KJKRFVW

[55] Rambabu T, Suneetha K. Prevalence of work related musculoskeletal disorders among physicians, surgeons and dentists: a comparative study. Annals of Medical and Health Sciences Research [Internet]. 2014 [cited 2018 Oct 16];4:578-82. Available from: https://doi.org/10.4103/ 2141-9248.139327

[56] Canadian Centre for Occupational Health and Safety. Working in a sitting position - good body position. Canadian Centre for Occupational Health and Safety 2018 [cited 2018 Oct 16]. Available from: https://www.ccohs. ca/oshanswers/ergonomics/sitting/sitting_position.html
[57] Wong SW, Smith R, Crowe P. Optimizing the operating theatre environment. ANZ Journal of Surgery [Internet]. 2010 [cited 2018 Oct 16];12:917-24. Available from: https://doi.org/10.1111/j.1445-2197.2010.05526.x

[58] Janki S, Mulder EE, IJzermans JN, Tran TK. Ergonomics in the operating room. Surgical Endoscopy [Internet]. 2017 [cited 2018 Oct 16];31:2457-66. Available from: https://doi.org/10.1007/s00464-016-5247-5

[59] Armstrong T, Yu D, Frischknecht A, Minter R, Andreatta P, Kasten S. Standardization of surgical procedures for identifying best practices and training. Work. 2012 [cited 2020 March 13]; Jan 1;41(Supplement 1):4673-9. Available from: https://doi.org/10.3233/WOR-2012-0108-4673

[60] Matern U. Ergonomic deficiencies in the operating room: examples from minimally invasive surgery. Work. 2009 [cited 2020 March 13]; Jan 1;33(2):165-8. Available from: https://doi.org/10.3233/WOR-2009-0862

[61] Seagull FJ. Disparities between industrial and surgical ergonomics. Work. 2012 [cited 2020 March 13]; Jan 1;41(Supplement 1):4669-72. Available from: https://doi. org/10.3233/WOR-2012-0107-4669

[62] Plessas A, Bernardes Delgado M. The role of ergonomic saddle seats and magnification loupes in the prevention of musculoskeletal disorders. A systematic review. International Journal of Dental Hygiene. 2018 [cited 2018 Oct 5];16:430-440. Available from: https://doi.org/10.1111/ idh. 12327

[63] Dorion D, Darveau S. Do micropauses prevent surgeon's fatigue and loss of accuracy associated with prolonged surgery? An experimental prospective study. Annals of Surgery [Internet]. 2013 [cited 2018 Oct 5];257:256-9. Available from: https://doi.org/10.1097/SLA. 0b013e31825efe 87

[64] Hallbeck MS, Lowndes BR, Bingener J, Abdelrahman AM, Yu D, Bartley A, Park AE. The impact of intraoperative microbreaks with exercises on surgeons: a multi-center cohort study. Applied Ergonomics [Internet]. 2017 [cited 2018 Oct 16];6-:334-41. https://doi.org/ 10.1016/j.apergo.2016.12.006

[65] Buck R, Wynne-Jones G, Varnava A, Main CJ, Phillips CJ. Working with musculoskeletal pain. Reviews in Pain [Internet]. 2009 [cited 2018 Oct 16];3:6-10. Available from: https://doi.org/10.1177/204946370900300103

[66] Gray H, Adefolarin AT, Howe TE. A systematic review of instruments for the assessment of work-related psychosocial factors (Blue Flags) in individuals with non-specific low back pain. Manual Therapy [Internet]. 2011 [cited 2018 Oct 17];16:531-43. Available from: https://doi.org/10.1016/j.math.2011.04.001

[67] Engel GL. The need for a new medical model: a challenge for biomedicine. Science [Internet]. 1977 [cited 2018 Oct 26];196:129-36. Available from: https://doi.org/ $10.1126 /$ science. 47460

[68] Cavanagh J, Brake M, Kearns D, Hong P. Work environment discomfort and injury: an ergonomic survey study of the American Society of Pediatric Otolaryngology members. American Journal of Otolaryngology [Internet]. 2012 [cited 2018 Oct 16];33:441-6. Available from: https://doi.org/10.1016/j.amjoto.2011.10.022 
Appendix

Excluded Studies and Rationale

\begin{tabular}{|c|c|c|}
\hline & EBSCO & \\
\hline 1 & $\begin{array}{l}\text { Vijendren, A., Devereux, G., Kenway, B., Duffield, K., Van Rompaey, V., } \\
\text { Van de Heyning, P. and Yung, M., 2017. Effects of prolonged } \\
\text { microscopic work on neck and back strain amongst male ENT clinicians } \\
\text { and the benefits of a prototype postural support chair. International } \\
\text { Journal of Occupational Safety and Ergonomics, pp.1-10. }\end{array}$ & $\begin{array}{l}\text { Not an objective measure } \\
\text { of posture }\end{array}$ \\
\hline 2 & $\begin{array}{l}\text { Rimmer, J., Amin, M., Fokkens, W.J. and Lund, V.J., 2016. Endoscopic } \\
\text { sinus surgery and musculoskeletal symptoms. Rhinology, 54(2), } \\
\text { pp.105-10. }\end{array}$ & Study design (survey) \\
\hline 3 & $\begin{array}{l}\text { Vijendren, A., Yung, M., Sanchez, J. and Duffield, K., 2016. Occupational } \\
\text { musculoskeletal pain amongst ENT surgeons-are we looking at the tip of } \\
\text { an iceberg?. The Journal of Laryngology \& Otology, 130(5), pp.490-496. }\end{array}$ & Study design (survey) \\
\hline 4 & $\begin{array}{l}\text { Williams Jr, K.L., Gupta, A.K. and Schultz, H., 2016. Ergonomics in hair } \\
\text { restoration surgeons. Journal of cosmetic dermatology, 15(1), pp.66-71. }\end{array}$ & Study design (survey) \\
\hline 5 & $\begin{array}{l}\text { Lakhiani, C., Fisher, S.M., Janhofer, D.E. and Song, D.H., } 2018 . \\
\text { Ergonomics in microsurgery. Journal of surgical oncology. }\end{array}$ & Study design (report) \\
\hline 6 & $\begin{array}{l}\text { Alqahtani, S.M., Alzahrani, M.M. and Tanzer, M., 2016. Adult } \\
\text { reconstructive surgery: a high-risk profession for work-related injuries. } \\
\text { The Journal of arthroplasty, 31(6), pp.1194-1198. }\end{array}$ & Study design (report) \\
\hline 7 & $\begin{array}{l}\text { Bolduc-Bégin, J., Prince, F., Christopoulos, A. and Ayad, T., } 2018 . \\
\text { Work-related musculoskeletal symptoms amongst Otolaryngologists and } \\
\text { Head and Neck surgeons in Canada. European Archives of } \\
\text { Oto-Rhino-Laryngology, 275(1), pp.261-267. }\end{array}$ & Study design (survey) \\
\hline 8 & $\begin{array}{l}\text { Lee, J., Kang, S.W., Jung, J.J., Choi, U.J., Yun, J.H., Nam, K.H., Soh, E.Y. } \\
\text { and Chung, W.Y., 2011. Multicenter study of robotic thyroidectomy: } \\
\text { short-term postoperative outcomes and surgeon ergonomic } \\
\text { considerations. Annals of surgical oncology, 18(9), pp.2538-2547. }\end{array}$ & Study design (survey) \\
\hline 9 & $\begin{array}{l}\text { Khansa, I., Khansa, L., Westvik, T.S., Ahmad, J., Lista, F. and Janis, J.E., } \\
\text { 2018. Work-Related Musculoskeletal Injuries in Plastic Surgeons in the } \\
\text { United States, Canada, and Norway. Plastic and reconstructive surgery, } \\
\text { 141(1), pp.165e-175e. }\end{array}$ & Study design (survey) \\
\hline 10 & $\begin{array}{l}\text { Wong, K., Grundfast, K.M. and Levi, J.R., 2017. Assessing work-related } \\
\text { musculoskeletal symptoms among otolaryngology residents. American } \\
\text { journal of otolaryngology, 38(2), pp.213-217. }\end{array}$ & Study design (survey) \\
\hline 11 & $\begin{array}{l}\text { Godwin, Y., Macdonald, C.R., Kaur, S., Zhelin, L. and Baber, C., } 2017 . \\
\text { The Impact of Cervical Musculoskeletal Disorders on UK Consultant } \\
\text { Plastic Surgeons: Can We Reduce Morbidity With Applied } \\
\text { Ergonomics?. Annals of plastic surgery, 78(6), pp.602-610. }\end{array}$ & Study design (survey) \\
\hline 12 & $\begin{array}{l}\text { Mendez, B.M., Chiodo, M.V., Vandevender, D. and Patel, P.A., } 2016 . \\
\text { Heads-up 3D microscopy: an ergonomic and educational approach to } \\
\text { microsurgery. Plastic and Reconstructive Surgery Global Open, 4(5). }\end{array}$ & Study design (survey) \\
\hline 13 & $\begin{array}{l}\text { Ayad, T., Peloquin, L. and Prince, F., 2005. Ergonomics in endoscopic } \\
\text { sinus surgery: systematic review of the literature. Journal of } \\
\text { otolaryngology, } 34(5) \text {, pp.333-340. }\end{array}$ & $\begin{array}{l}\text { Study design (systematic } \\
\text { review) }\end{array}$ \\
\hline
\end{tabular}

